\title{
Development of design methodology for mechanized harvesting and pruning of shrubs
}

\author{
R. V. Praveena Gowda ${ }^{1}$, A. N. N. Murthy ${ }^{2}$ and E. Muniraju ${ }^{3}$ \\ ${ }^{1}$ Dept. of Industrial Engineering \& Management, Dayananda Sagar College of Engineering, Bangalore-78, India \\ ${ }^{2}$ T. John Institute of Technology, Bangalore-83, India, ${ }^{3} \mathrm{KSSRDI}$, Thalagattapura, Bangalore-61, India \\ annmiem@yahoo.com, praveena_gowda@rediffmail.com, emuniraju@yahoo.com
}

\begin{abstract}
A mulberry harvesting machine and harvesting \& pruning machine have been designed newly to suit for sericulture use which save cost and labour. The machines were tested in local field and suit better. Sericulture or silk culture is a labour intensive rural industry. At present it faces a shortage of labour force. Harvesting and pruning of mulberry plants are the most critical activities involved in sericulture. In the survey, $80 \%$ sericulturists felt that the harvesting and pruning are most tedious and stressful activities. The main reasons are high work stress, less rest and health problems associated with it. Hence, labourers show less interest towards sericulture. Hence, mechanized way of harvesting and pruning may be an alternative approach to minimize the problem. The Japanese scientists developed a harvesting and pruning equipment attached to tiller. This machine has certain limitation to Indian cultivation. Hence, a design methodology has been framed to develop mechanized mulberry plant harvesting and pruning system to suite Indian mulberry plantation and at the same time cost effective.
\end{abstract}

Keywords: Sericulture, mulberry plantation, India.

\section{Introduction}

Agriculture production has its own unique ergonomic hazards and musculoskeletal injury problems. Although some hazards are similar throughout, each activity imposes unique and specific demands on the conditions of workers. Risk exposure analysis of farm workers related to different crops and commodities clearly demonstrates the involved risk factors and available preventive methods in the form of work practices or labour aids. However, the problem is little recognized and is not given priority for risk preventive research by most of the farm safety research organizations. The three general risk factors as both endemic and of highest priority throughout the agricultural industry are: lifting and carrying heavy loads (over $50 \mathrm{lb}$ ); sustained or repeated full body bending (stoop); and very highly repetitive hand work (clipping, cutting). Mulberry cultivation, an agriculture activity is not exempted from the risk factors. During the process the mulberry shoots are harvest manually once in $45 \mathrm{~d}$ using sickle or secateur in kneel down or bending posture and fed to rear silkworms. This is very tedious and stress full activity. During mulberry harvesting, care should be taken that the branches are cut properly and

Research article

CIndian Society for Education and Environment (iSee)
Fig. 1.Design methodology
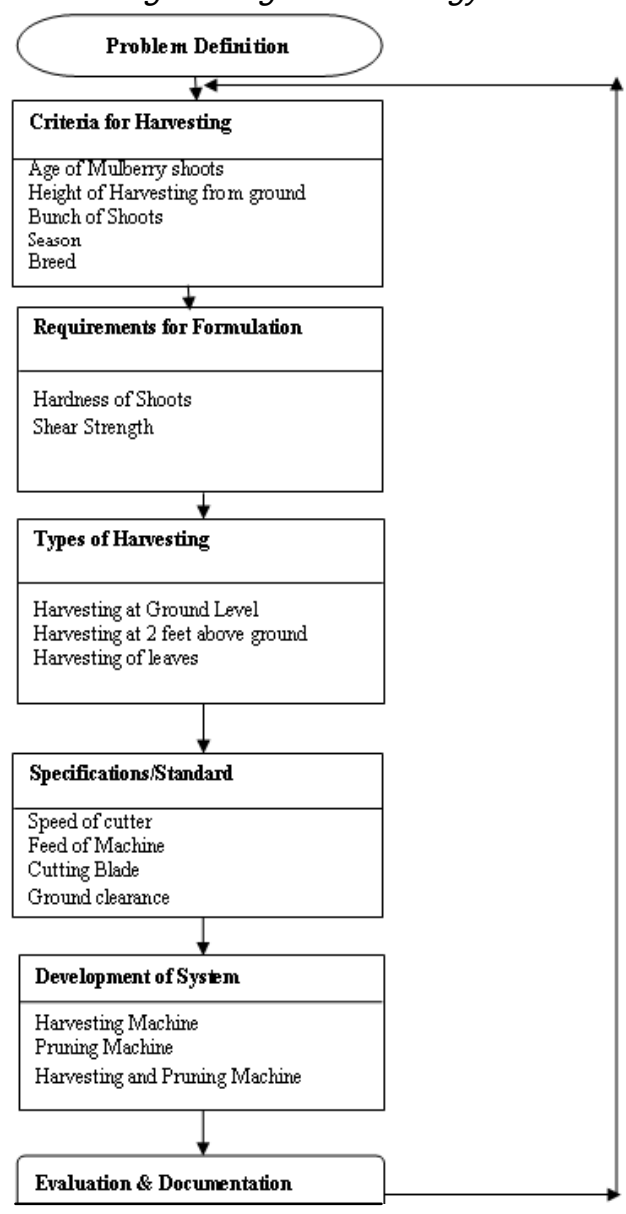

"Mechanized mulberry harvesting" http://www.indjst.org the operation does not damage the bark of the branches which are left in the plant, this is necessary to ensure sprouting and regrowth of branches.

Problem definition (Fig.1)

Mulberry plants need harvesting at regular intervals for good growth and production of nutritious leaves. The pruning of mulberry plants after harvesting leaves is carried out manually. Manual harvesting is not only time consuming but also involves drudgery. In manual harvesting about 4-5 man-days are required to harvest one acre (10-12 man-days per hectare) of mulberry garden. Manual harvesting is economically justified and feasible for small gardens but not for large scale mulberry cultivation. In addition, improper and unscientific shoot pruning and harvesting also leads to plant damage, pathogen entry and death of the plant (Verma \& Dandin, 2006; 2010). In manual harvesting it has been observed that rearers harvest only soft branches which lead to development of a crown at a height of 30 to $40 \mathrm{~cm}$ from ground. The crown gives rise to a number of branches, 
which may not have healthy leaves. It is therefore essential to cut periodically the crown for good branching. Cutting crown is an energy and time consumed in the operation. In manual harvesting it has also been noticed that a large number of buds are damaged due to peeling of bark, splitting of branches due to reduced sharpness and wearing out of teeth (Shankar, 1997; Anonymous, 2003). To overcome the above said problems, a design methodology has been developed, and compared with

Fig. 2. Levels of difficulties in sericulture operations.
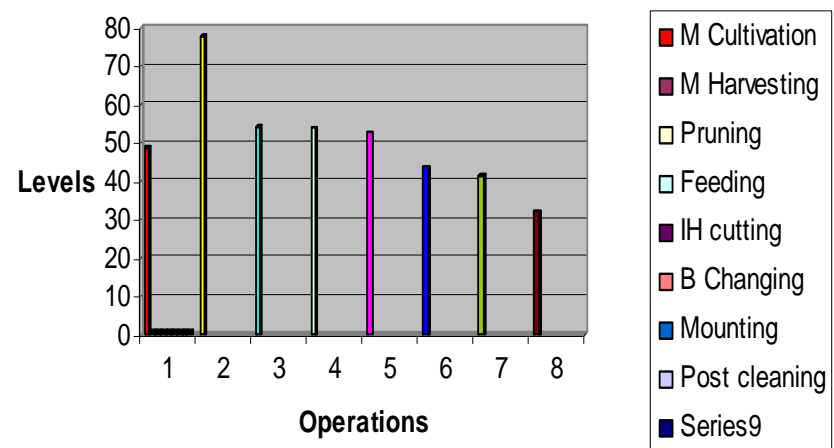

the traditional sickle and secateurs harvesting methods. A survey was conducted to know the present status of tools and new technology adapted in sericulture to overcome labour shortage. Questioner comprising of 33 questions was prepared. Feedback was taken from 200 respondents (Sericulturists) located in Karnataka who actually face the difficulties in harvesting and pruning of the mulberry plants in sericulture.

The data about difficulty of operations are analyzed by giving 8 points for 1,7 points for 2 and so on the bars shown on Fig. 2 that $2^{\text {nd }}$ operation, mulberry harvesting takes maximum weight age with $78 \%$ more difficult one among other 7 major operations. The next highest one is pruning with $53 \%$ and so on. Mulberry plants need accurate harvesting at Crown Point of stem at regular intervals for good growth of better buds and production of nutritious leaves. Manual harvesting is not only time consuming but also involves drudgery. Manual harvesting is economically justified only for small gardens but for large scale cultivation it is very apt to use mechanized method of harvesting and punning.

\section{Requirements formulation}

The detailed data was collected regarding the physical properties of mulberry plants at different ages.

Hardness number

Initially the mulberry plant stem cut to the specimen size of the Janka hardness tester. The hardness was determined at $12 \%$ moisture content. This was conducted at Wood Research Centre, Bangalore. Mulberry stem
Vol. 4 No. 2 (Feb 2011)

ISSN: 0974- 6846

(Common name Mora, Scientific name Mora spp.) had Janka hardness number shown in Table 1. Agronomic characters

The various physical characteristics are collected from sources at the plant height of 2.06 $\mathrm{m}$. Agronomic characters of mulberry varieties at 20 weeks after transplanting are very important to know the growth of plant. The mulberry variety Morus nigra has \begin{tabular}{l|c|c|c|c}
3.4 & 20 & plant height of $2.60 \mathrm{~m}$, stem \\
diameter of $25 \mathrm{~mm}$, internodal length of $37.2 \mathrm{~mm}$.
\end{tabular} Average number of branches about 4.7 and leaf mass of

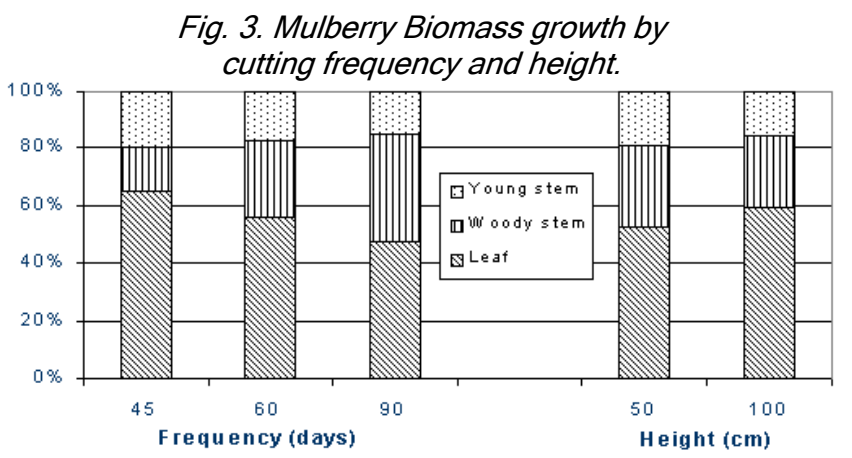

$2.45 \mathrm{~g}$. Whereas other species (actually used in sericulture) has plant height of $2.72 \mathrm{~m}$, stem diameter of $25 \mathrm{~mm}$, internodal length of $42.1 \mathrm{~mm}$. Average number of branches is about 2.3 with leaf mass of $2.82 \mathrm{~g}$ (Gupta \& George, 2006). These results are closely linked to the growth process, by which scalar enchymatous tissues increase proportionally to age.

Shear strength

The test was conducted to know the sheer force requirement at different ages of plant (Fig.3). Both harvesting and pruning operations were carried out using UTM setup and results are tabulated (Table 1).

Velocity and feed rate of cutting (Fig.4)

A semi-automated speed controlling device for machine tools has been designed to vary the speed of the cutter with a constant feed rate of the job depending on the hardness and strength of the material. This prototype is concerned with the machining of different types of wood. It consists of a $1 \mathrm{HP}$ variable speed DC motor, Tachogenerator, 8" tungsten carbide tip cutter, a motor for the automatic feeding mechanism has been used. Project is concerned with the study of existing methods of machining; finding the alternate techniques for the speed control, pilot study of a new machine, cost analysis, designing the prototype and finally the testing is done keeping the few constraints in view.

Types of harvesting

The harvesting of mulberry plants includes various types such as: 1) Plants are cut at ground level as it is followed in most of the places in Kolar region. 2) Plants are cut at about 2 feet above ground level and 3) Leaf 
Indian Journal of Science and Technology

Fig. 4. Analysis of speed v/s feed rate of mulberry shoot cutting at different ages.

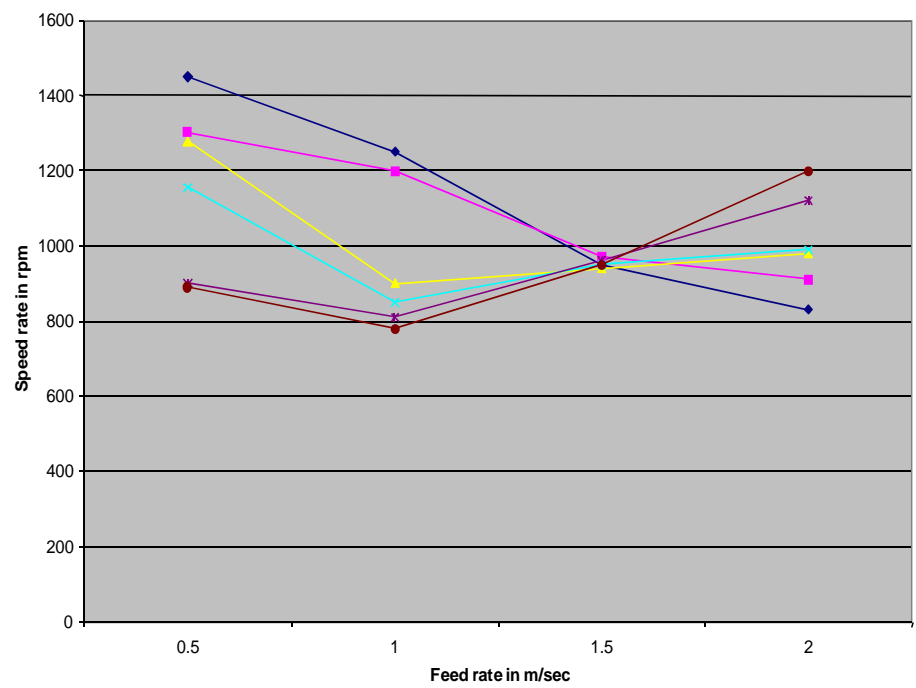

harvesting this does not require harvesting of plant but upper pruning is required.

Harvesting at ground level

Each types of mulberry plant harvesting needs specific shear force to cut the stems. The ground level harvesting is usually done at the age between 45 to $75 \mathrm{~d}$ after previous harvesting. In this type the stem growth in diameter size is between $1 \mathrm{~cm}$ to $2.5 \mathrm{~cm}$ and the fiber strength is about $1 \mathrm{~N} / \mathrm{mm}^{2}$. The appropriate cutting speed required to harvesting at this stage need to be evaluated through new automatic mechatronics setup.

Harvesting at 2 feet above ground level

The pit system of mulberry cultivation is nowadays getting popularized. In this type, the plants are cut to 1-2 feet above the ground level. The bud growth is faster and also the gap between two mulberry harvests is less. As there is no waste of leaves at lower end of plants, full leavf length is used to feed directly to silk worms due to non existence of dirty and aged leaves at the bottom end of plants. The mulberry shoots are cut during 30 to $45 \mathrm{~d}$ age after previous harvesting. The shear force (about 0.5 to $0.7 \mathrm{~N} / \mathrm{mm} 2$ ) required is slightly less compare to ground level harvesting type. The appropriate speed of cutter needs to be evaluated using automatic mechatronics setup.

\section{Leaf harvesting}

The leaf harvesting plants need upper pruning to cut post harvested shoots once in a year and ground pruning at ground level once in 4 years. Both upper and ground pruning need more shear force as the stems fiber is harder due to aging.

\section{Standards and specifications}

The optimized feed is derived from experimentations, as the harvesting of all type of mulberry shoot ages come close to speed of cutter about $960 \mathrm{rpm}$. Hence, it is essential to have cutter speed at $960 \mathrm{rpm}$ with feed rate of $1.5 \mathrm{~mm} / \mathrm{sec}$.
Vol. 4 No. 2 (Feb 2011)

ISSN: 0974- 6846

Force required for operation in worst condition (Lingaiah \& lyengar, 2006):

$\mathrm{F}(\mathrm{req})=$ force due to stress + resistance offered by land+ vibration of machine

$=\left\{\Gamma /\left(\pi \mathrm{d}^{2} / 4\right)^{*} A c\right\} \mathrm{N}+20 \mathrm{~N}+10 \mathrm{~N}$

$=353 \mathrm{~N}+20 \mathrm{~N}+10 \mathrm{~N}=383 \mathrm{~N}$

Maximum bearable force:

$F(\max )=n\left(12^{2} / 4\right)^{*} 156$ (for M.S. $\left.\sigma y=156 \mathrm{~N} / \mathrm{mm}^{2}\right)=$ $17699 \mathrm{~N}$

Since $F(\max )>>F(r e q)$

Hence design is safe.

Shear force required to cut shoots of $10 \mathrm{~mm}$ diameter

Shear stress $=0.8 \mathrm{~N} / \mathrm{mm}^{2}$

Therefore $T($ req $)=\left(3.14^{*} \mathrm{D}^{3} / 16\right)^{*}$ Shear force $=$ $0.157 \mathrm{~N}-\mathrm{m}$

Torque produced by motor:

Given $\mathrm{P}=\left(2{ }^{*} 3.14^{*} \mathrm{~N}^{*} \mathrm{~T}\right) / 60$;

$\mathrm{T}=\left(\mathrm{P}^{*} 60\right) /\left(2^{*} 3.14^{*} \mathrm{~N}\right)$

$\mathrm{N}-\mathrm{m}=0.237 \mathrm{~N}-\mathrm{m}$

Since, $T$ (req) $<T$ (act),

Hence, design is safe.

Shear stress required to cut the shoots of $10 \mathrm{~mm}$ dia:

Shear stress $=0.8 \mathrm{~N} / \mathrm{mm}^{2}$

Shear stress $=$ Force $\left(F_{S}\right) /($ cross sectional area of shoots $)$

Force $=\mathrm{F}_{\mathrm{S}}=62.8 \mathrm{~N}$

Torque transmitted by motor:

$\mathrm{T}=$ (Force applied by motor) $^{*}$ (radius of shaft)

$\mathrm{F}_{\mathrm{M}}=78.48 \mathrm{~N}$

Since, $F_{M}>F s$,

Hence design is safe.

Torque required to cut the mulberry shoots found by experiment on universal testing machine. Shear force required to cut shoots of $15 \mathrm{~mm}$ dia. $\zeta=1 \mathrm{~N} / \mathrm{mm}^{2}$.

Therefore $T($ req $)=(\Pi \mathrm{d} 3 / 16) \Gamma=622.67 \mathrm{~N}-\mathrm{mm}=0.663 \mathrm{~N}-\mathrm{m}$ Specification of motor:

Given $P=(2 \sqcap \mathrm{NT}) / 60$

$\mathrm{T}=\left(\mathrm{P}^{*} 60\right) /(2 \Pi \mathrm{N}) \mathrm{N}-\mathrm{m}$

$\mathrm{T}=(2.72 * 10 * 10 * 10 * 60) /\left(2 \Pi^{*} 8000\right) \mathrm{T}(\mathrm{act})=2.387 \mathrm{~N}-\mathrm{m}$ since, $T($ req $)<<T($ act) Hence design is safe.

Specification of power screw: It is taken a standard power screw of

Nominal dia $20 \mathrm{~mm}$

Bolt dia of $20 \mathrm{~mm}$

Nut dia of $20.5 \mathrm{~mm}$

Minor dia of $18 \mathrm{~mm}$

Pitch of $2 \mathrm{~mm}$

Area or core area $A c=201 \mathrm{~mm}^{2}$

Coefficient of friction 0.12

Thickness $\mathrm{e}=1 \mathrm{~mm}$

Tan $\alpha=1 / \pi^{*} \mathrm{~d} 2$

$2 / \Pi * 20.5=0.03104$

Principal stress $\Psi_{\mathrm{C}}=\mathrm{W} / \mathrm{Ac}=10000 / 201=49.75 \mathrm{~N} / \mathrm{mm}^{2}$

Torsional moment. Mts $=\mathrm{W}^{*}\left\{\mathrm{~d} 2 / 2^{*}\left[(\operatorname{Tan} \alpha+\mu) /\left(1-\mu^{*}\right.\right.\right.$ Tan $\alpha)]\}=10000^{*}\left\{20.5 / 2^{*}\left[(0.03104+0.12) /\left(1-.12^{*} 0.03104\right)\right]\right\}$

$=15539.48 \mathrm{~N}-\mathrm{mm}$

Mts $=\pi / 16^{*} \tau^{*} d^{3}$ 


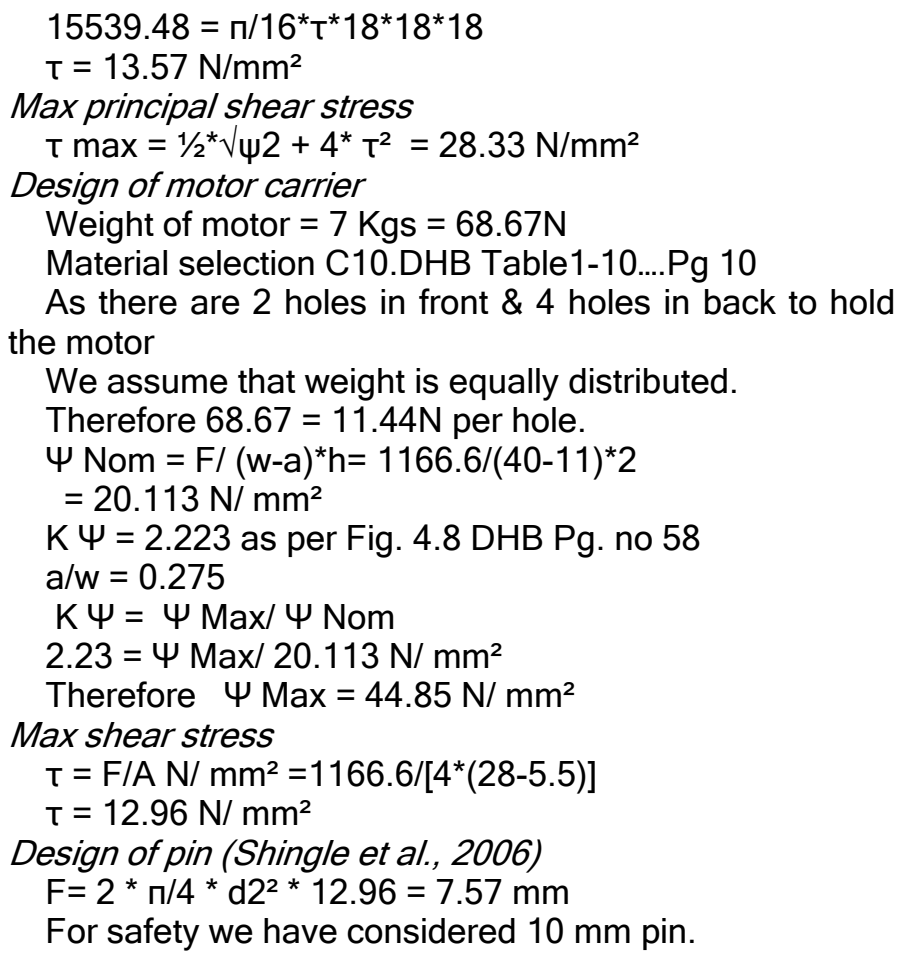

For safety we have considered $10 \mathrm{~mm}$ pin.

\section{Search for alternative solutions}

Since the mulberry plants are harvested at different ages starting from $45 \mathrm{~d}$ to $90 \mathrm{~d}$ with different types and pruning is from 1 year to 3 years with different types, the different harvesting and pruning tools are required to cater all types. The Four type of harvesting and pruning systems are designed and developed for various types of mulberry plants harvesting and pruning.

\section{Harvesting machine (Fig.5)}

Fig. 5. Mulberry harvesting machine

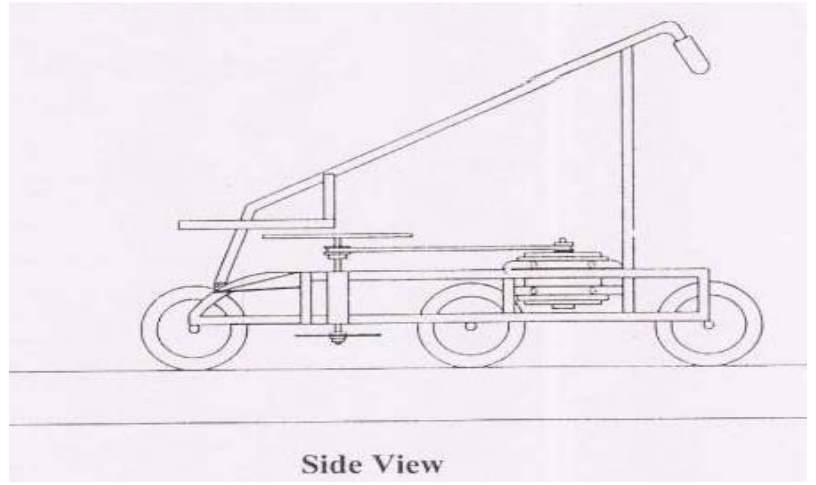

The harvesting machine is designed and developed to meet the requirement of only harvesting. It has adjustable blade which can be shifted from ground harvesting to upper harvesting. The spindle of the blade is connected to $1 \mathrm{hp} \mathrm{AC}$ electric motor of speed $8000 \mathrm{rpm}$ through $\mathrm{V}$ belt drive. The hole setup is mounted on single row of three wheels. The moment is manually pushed by operator. This harvesting machine is meant only for harvesting soft mulberry plants at the age less than $60 \mathrm{~d}$.

Pruning conditions.
The ground harvesting is done very effectively using this harvesting machine. This machine is eco-friendly, which operates with single phase AC electric power.

Harvesting \& pruning machine (Fig.6)

Upgraded mulberry harvesting and pruning machine has been newly design and developed. This is ergonomically designed to suite at labourers physical nature and most flexible to all type of mulberry harvestings. This machine is eco-friendly, which operates with single phase $A C$ electric power.

\section{Evaluation and documentation Harvesting machine and harvesting \& pruning machine}

Fig. 6. Upgraded mulberry plant harvesting and pruning machine.

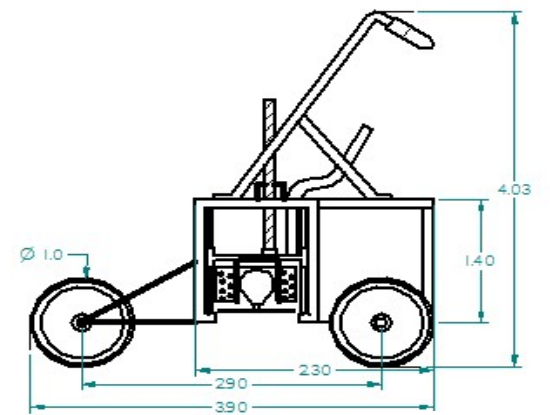

LSV

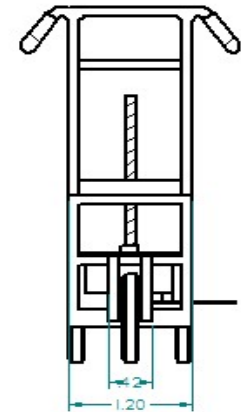

FV

The field test was conducted for an acre of plantation ( 1 acre $=0.4$ hec. appr.) as a pilot study comparing the manual cutting using sickle/scissor with harvesting machines. Data collected has shown in table for area covered during cutting process by both methods (Fig.7).

If new machine is used then harvesting is not required so number of labour is zero (Fig.8) and then harvesting is not required so operation cost is zero (Fig.9).

Upper pruning: For mulberry plants this process is done 5 times in a year, it takes place after $7 \mathrm{~d}$ of harvesting. The data is collected per acre operation (Fig.10, 11,12,13).

Ground pruning: This is done once in 2 years so as to get fresh stem for better quality buds (Fig.14, 15,16,17).

\section{Communication of the results}

The harvesting and pruning machine has been field tested and showed better results. The pruning operation done with this machine eliminates $90 \%$ of manual labour and also provides better re-budding of mulberry plant stumps. This machine saves nearly $70 \%$ labour requirements during mulberry plant harvesting and thus eliminates any possible injuries to labourers. The developed machine is quite simple and easy to use. In addition, it reduces the drudgery of harvesting and difficulties involved in working at varied climatic 
Indian Journal of Science and Technology

Fig. 7. Manpower required in

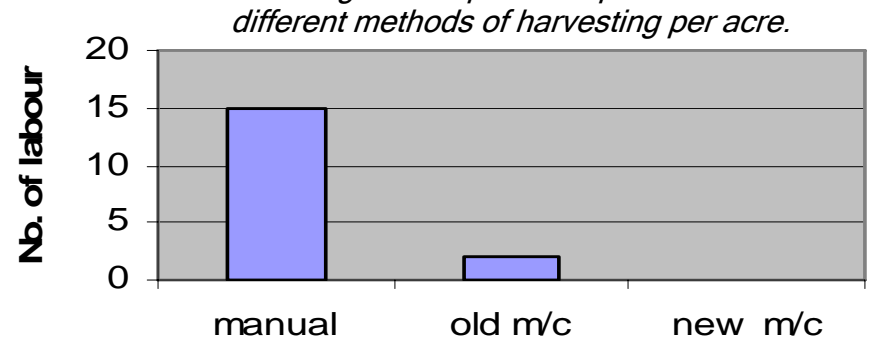

Type of harvesting

Fig. 8. Cost per acre by

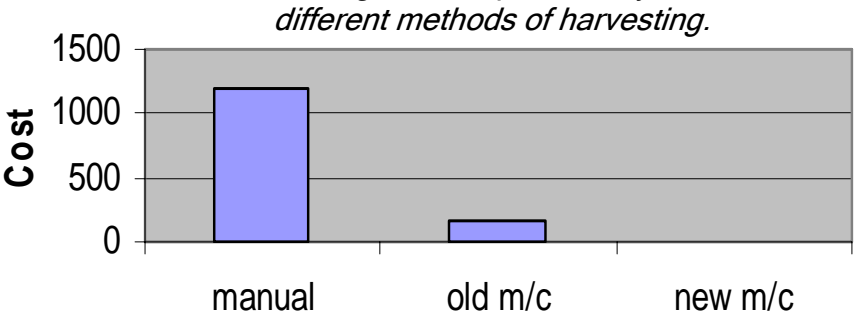

Type of harvesting

Fig. 9. Time taken in harvesting

by different methods per acre.

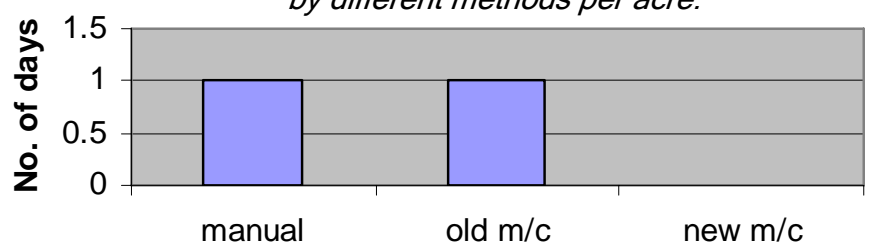

Type of harvesting

Fig. 11. Manpower utilization per acre for upper pruning

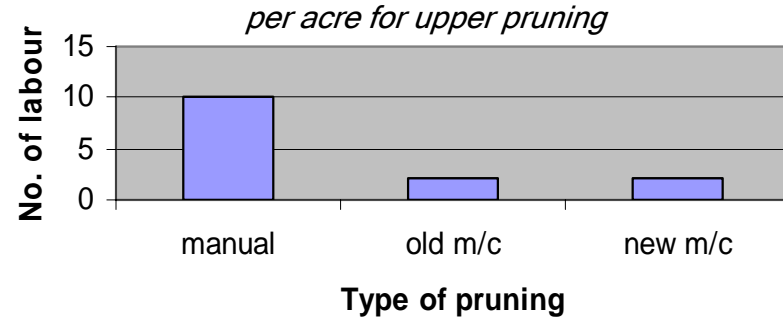

Fig. 12. Cost ( Rs.) per acre for upper pruning

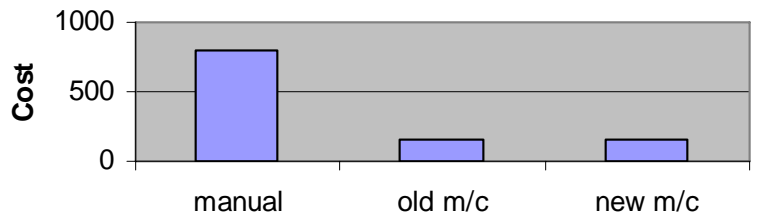

Type of pruning

Fig. 13. Duration in days for upper pruning per acre.

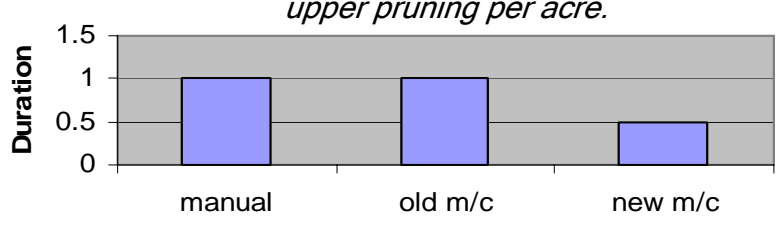

Type of pruning

Research article

CIndian Society for Education and Environment (iSee)
"Mechanized mulberry harvesting" http://www.indjst.org
Vol. 4 No. 2 (Feb 2011)

ISSN: 0974- 6846

Fig. 10. Upper pruning.

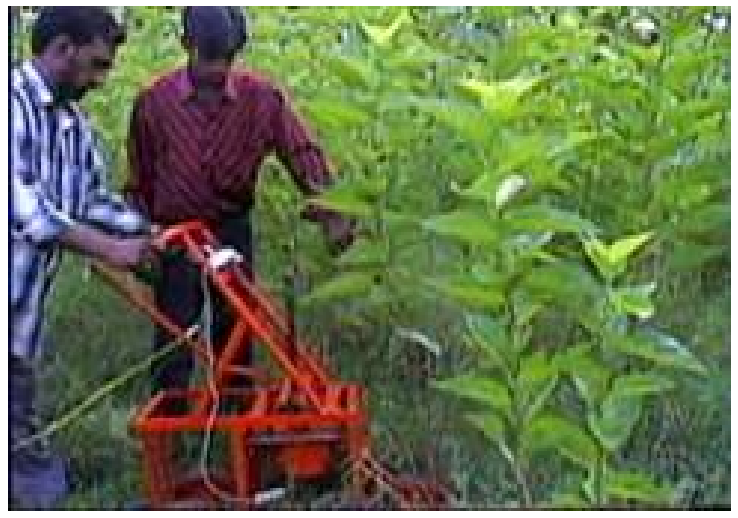

Fig. 14. Pruning operation.

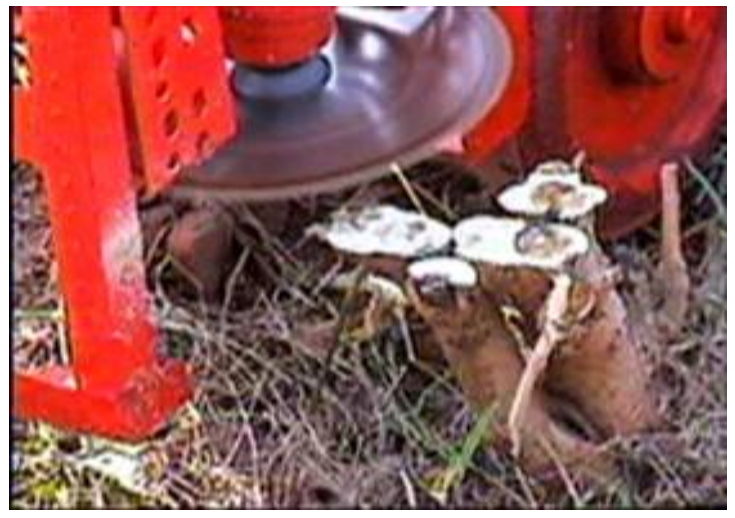

Fig. 15. Ground pruning cost in Rs. per acre.

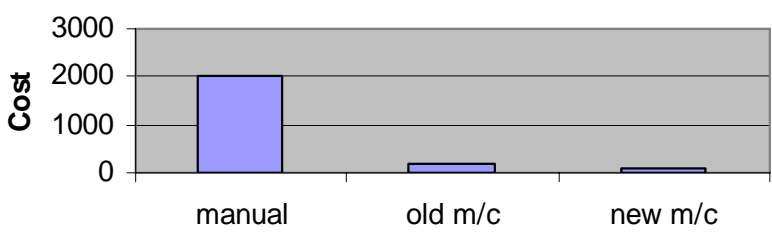

Type of pruning

Fig. 16. Duration in days for ground pruning per acre

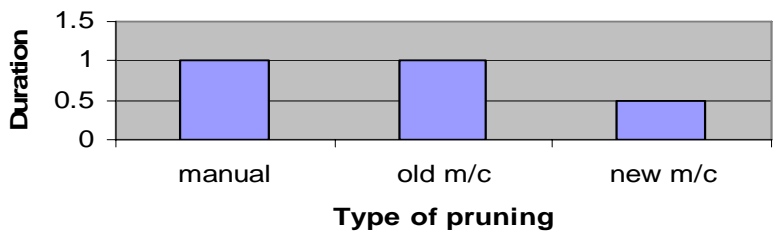

Fig. 17. Manpower utilization per acre for ground pruning

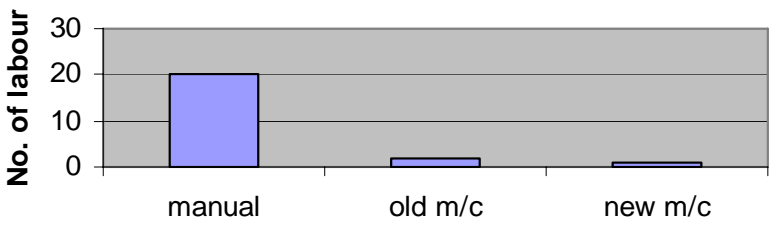

Type of pruning

Praveena Gowda et al. Indian J.Sci.Technol. 


\section{References}

1. Anonymous (2003) Seri business-A users guide: Farm sector, Pub. Member secretary, CSB, Bangalore: p332.

2. Dandin SB and Verma S (2002) Mechanization in sericulture - Need \& scope. Indian Silk. 41(1), 9-12.

3. Dandin SB and Verma S (2002) Workshop on mechanization in sericulture. Indian Silk. 40(12), 27-28.

4. FAO (1988) Mulberry cultivation. FAO Agri. Services Bull. 73/1, Rome. p:127.

5. Gupta M and George D (2006) Evaluation of agronomic characters of mulberry varieties in south east Queensland Loko Anota, School of agriculture and horticulture, University of Queensland, Gatton, Qld 4343, 2-3.

6. Lingaiah K and lyengar BK (2006) Design data hand book, vol. I, chapter 1 \& 2, Suma publishers, Bangalore, India. pp:28-62.

7. Malmqvist J, Axelsson R and Johansson M (1996) A comparative analysis of the theory of inventive problem solving and the systematic approach of pahl and beitz. Irvine, California. 1, 7-8.

8. Muniraju E and Mundkur R (2008) Directory of sericulture technologies, KSSRDI, Bangalore. p:1100.

9. Ramakant (1996) Mechanization of mulberry cultivation in Japan. Indian Silk. 39(9), 39-41.

10.Sanchez MD (2008) World distribution and utilization of mulberry potential for animal feeding, animal production office. Animal production and health division FAO, Rome, Italy 1.

11.Shankar MA (1997) Hand book of mulberry nutrition, Pub by multiplex, Karnataka agro chemicals, Bangalore: $\mathrm{p}: 126$.

12.Shingle JE and Ulcker JJ (1981) Theory of machinery and mechanisms, Mc Graw hill, $2^{\text {nd }}$ edn. India. pp:410418.

13. Shingle JE, Budynas RG and Nisbett JK (2008) Mechanical engineering design. $4^{\text {th }}$ edn., Pub. TATA Mc Graw hill - India. 85-97.

14.Singh GB (1995) Mechanization in silkworm rearing. Indian Silk. 35(2), 21-25.

15.Verma S and Dandin SB (2006) Mechanization in sericulture, pub. Director, CSRTI, Mysore. p:78

16.Verma S and Dandin SB (2010) Hand book of sericulture: Mechanization in mulberry cultivation, Edt. Dandin SB and Giridhar K. Pub. Member secretary, CSB, Bangalore. 